\title{
Mitigation of dermal auto immune disease through combined action of natural constituents: An advantageous over allopathic medicines
}

\author{
Kuntal Das», Adnan A. Khan*, V. Gowthami, Vivek Sharma and S. Yahya Ahmed \\ Krupanidhi College of Pharmacy, Department of Pharmacognosy and Natural Product Chemistry, \#12/1, Chikkabellandur, Carmelaram Post, \\ Varthur Hobli, Bangaluru-500035, Karnataka, India \\ *Division of Nephrology and Hypertension, Department of Medicine, University of California, San Diego, Suite Plaza 1, 4510 Execute Drive, \\ San Diego-92121, USA
}

\section{Article Info}

Article history

Received 1 March 2020

Revised 25 April 2020

Accepted 28 April 2020

Published online 30 June 2020

Keywords

Bauhinia variegata (L.) Benth.

Phlebodium decumanum (Willd.) J. Sm.

PSI

Psoriasis

epidermal thickness

Quercetin

\begin{abstract}
The present study was aimed for the phytochemical screening of Phlebodium decumanum (Willd.) J. Sm. (PD) and Bauhinia variegata (L.) Benth. and their synergistic efficacy for the treatment of psoriasis. Herb extract ratio followed by Pharmacognostical screening for both the plants (PD and BV). Thereafter, TLC was performed to detect the constituents. Furthermore, two different dose levels (200 $\mathrm{mg} / \mathrm{kg}$ b.w., and $400 \mathrm{mg} / \mathrm{kg}$. b.w.) were used for both the methanol extracts (based on acute toxicity study) and the result was compared with standard Rentino A $(0.05 \%)$. Psoriasis severity index (PSI) according to the phenotypic changes (redness, erythema, and scales) and histological features (epidermal thickness) were evaluated for 28 days. Finally, the correlation study was performed between the activity, yield of extract and constituent present. Series of chemical tests revealed the presence of alkaloids, flavonoids, steroids and polyphenols in both PD and BV plants and based on the chemical nature further Quercetin (flavonoid) was isolated from both the plants. Further, resulted progressive reduction $(p<0.05)$ in the severity of psoriatic lesions (redness, erythema, and scales from histopathology study) from the $7^{\text {th }}$ day to the $28^{\text {th }}$ days and decreased epidermal thickness in animals treated with combined extracts at a dose of $400 \mathrm{mg} / \mathrm{kg}$ b.w. Finally, the result concluded that the isolated Quercetin showed significant antipsoriasis activity when compared with the combination of methanolic extract of both the studies plants by the mechanism of inhibition of the keratinocyte proliferation.
\end{abstract}

\section{Introduction}

Psoriasis is a chronic disease on skin with extra skin cells. It forms scales and red patches which are silver coloured, itchy and also sometimes painful. It is an auto immune disease which forms in any age group of people, provoked by various triggers such as mild trauma, sunburn, infections, stress and even by systemic drugs (Boehncke and Schon, 2015). It is mainly located on the elbows, knees and scalp but people are not taking seriously the dermatitis which may sometimes has connection with arthritis, myopathy, enteropathy, spondylitic heart disease, diffuse cutaneous and mucosal pustules and electrolyte disturbances etc. (Samuel et al., 1986). Of late, psoriasis is a serious global problem due to unavailability of proper treatments to cure psoriasis from root level (Roberson and Bowcock, 2010) and even the treatments are totally based on controlling the symptoms of the disease. Recent market survey revealed about 25 million people living with psoriatic disease in Worldwide which is $2-3 \%$ of the total population and the same is increasing day-by-day due to negligence (Figure 1). Different

Corresponding author: Dr. Kuntal Das

Professor, Krupanidhi College of Pharmacy, Department of Pharmacognosy and Natural Product Chemistry, \#12/1, Chikkabellandur, Carmelaram Post, Varthur Hobli, Bangaluru-500035, Karnataka, India

E-mail: drkkdsd@gmail.com

Tel.: +91-9632542846

Copyright (C) 2020 Ukaaz Publications. All rights reserved.

Email: ukaaz@yahoo.com; Website: www.ukaazpublications.com treatment strategies are available with synthetic medicines but affordability, availability, and prolonged side effects for the psoriasis still a challengeable task (Kim and Del Rosso, 2010). Therefore, treatment based on the natural products is now recent trend which showed much better therapeutic efficacy and also curing psoriasis for long. Herbs or herbal formulations in sole or in combinations are less expensive and are free from risk of side effects that created the interest as a viable alternative of allopathic medicines for psoriasis treatment (Deng et al., 2014, Das et al., 2019). Therefore, in the present study two important plants were selected (Bauhinia variegata (L.) Benth. and Phlebodium decumanum (Willd.) J.Sm.) for treatment of psoriasis and established potent drug combination as antipsoriasis activity. Bauhinia variegata (BV) is a common flowering tree which is abundantly available in roadside throughout India, belongs to the family Fabaceae. The plant is commonly known as Kanchan or Cow's paw (Kirtikar and Basu, 1999) whereas, Phlebodium decumanum (PD) is commonly known as the ornamental fern, belongs to the family Polypodiaceae, is abundantly available in damp regions in many parts of India (Das et al., 2017). Traditionally BV plant is antidiabetic, antiulcer, antioxidant, nephroprotective, hepatoprotective as well as Immunomodulatory (Patil et al., 2010; Panda et al., 2011) which are due to the presence of some important phytoconstituents, viz., Lupeol, $\beta$-Sitosterol, Kaempferol and Quercetin (Jash et al., 2014) and other constituents like terpenoids, tannins, saponins, reducing sugars, steroids and cardiac glycosides (Gupta et al., 1980; Al-Shafi, 2013). In other 
plant (PD), it was reported that the leaves contains alkaloids, flavonoids, various fatty acids like oleic acid, linoleic acids, linolenic acids, arachidonic acid, eicosapentaenoic acid, ecdysone; ecdysterone, kaempferols, and melilotoside (Das and Einstein, 2007) and due to presence of these constituents, PD is effective drug as anti-inflammatory (Punzon et al., 2003), antioxidant (Díaz-Castro et al., 2012), wound healing, immune system improving (GonzalezJurado et al., 2011), antimicrobial, anthelmintic (Das et al., 2017) etc. It was reported that combined plant extract always showed effective synergistic effects on any therapeutic activity (Hosoya,
1988; Das et al., 2019; Kaur et al., 2019) and based on this concept, two medicinal plants were selected in the present study. Furthermore, it was also confirmed that therapeutic efficacy mainly based on presence of phytoconstituents where flavonoids are played major role in any important activity. There are no reports as antipsoriasis activity on these two plants in combinations. It was observed that in both the plants flavonoids are present and due to that they both show immunomodulatory activity and hence based on that concept the present study was carried out to investigate methanol extract of BV and PD for effective antipsoriasis activity.

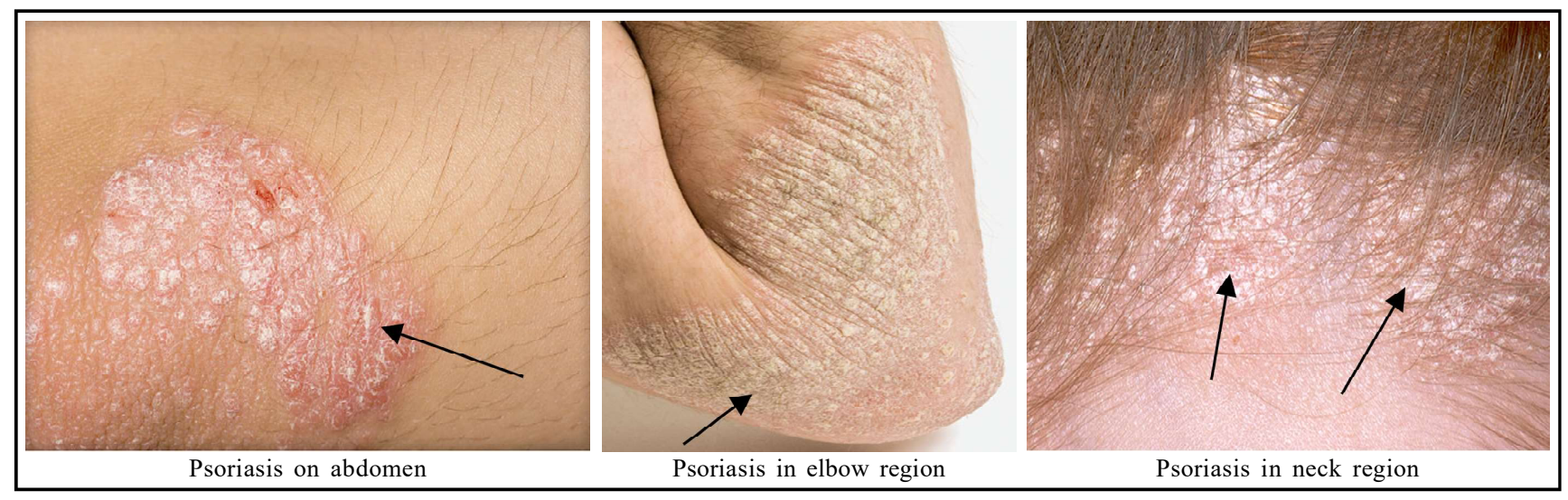

Figure 1: Psoriasis in human skin.

\section{Materials and Methods}

\subsection{Authentication and preparation of plant samples}

The leaves of the BV and PD were taxonomically identified and authenticated by Dr. Rajasekharan PE, Principal Scientist, Department of Plant Biotechnology, Indian Institute of Horticultural Research, Bengaluru. The voucher specimens of both leafy twigs were collected from Bengaluru, Karnataka (KCP/38/BEN-PD/201819; KCP/39/BEN-BV/2018-19) have been preserved in Dept. of Pharmacognosy, Krupanidhi College of Pharmacy, Bengaluru as herbarium for future reference.

The leaves of both the plants were collected in September, 2018 from Indian Institute of Horticultural Research, Bengaluru for further investigation. The leaves were cleaned with running tap water and shade dried for 15 days with daily observation for absorption of moisture. The dried leaves were blended in a mixer grinder into a coarse powder and separately kept in air tight sealed plastic containers, labeled properly for further study.

\subsection{Preparation of plant extracts and their phytochemical screening}

$200 \mathrm{~g}$ of dried powdered samples were extracted separately by soxhlet method using methanol as solvent at $45^{\circ} \mathrm{C}$ for $8 \mathrm{~h}$. Thereafter, extracted liquids were filtered with Whatman No. 1 filter paper and evaporated at $45^{\circ} \mathrm{C}$ and stored in refrigeration condition $\left(\right.$ at $\left.4^{\circ} \mathrm{C}\right)$ in glass bottles for further study. The yield of extracts was calculated and then the presence of various phytochemicals was screened qualitatively by various chemical tests for the detection of various phytoconstituents as per the method described by the earlier researchers (Harborne, 1998; Sazada et al., 2009).
Thereafter, presence of Quercetin (flavonoid) was identified with the TLC (Thin layer chromatography) by the standardization of the method. Further, isolated using column chromatography with the help of various solvents based on polarity and finally identified by UV-Vis spectrophotometer and FT-IR. This identification was essential for greater correlation with the anti psoriasis activity and established possible mechanism of action.

\subsection{Selection of animals}

Healthy albino mice with body weight of 50-70 g, were used for the present study, obtained from Krupanidhi Pharmacy institutional animal house. The animals were housed in polypropylene cages and were left for 7 days for acclimatization to the animal room. During that time animals were kept under controlled conditions (12 h light/dark cycle at $22 \pm 2^{\circ} \mathrm{C}$ ) and fed on standard pellet diet and water ad libitum. Animals were ethically taken care of as per the CPCSEA guidelines of with approval from the Institutional Animal Ethics Committee (KCP/PCOL/05/2018).

\subsection{Acute dermal toxicity}

Acute dermal toxicity studies were carried out in accordance with the Organization for Economic Cooperation and Development guidelines no. 402 (OECD, 2001). The mice (six animals per group) were divided into two groups. The animals' hair was removed from the dorsal portion of the body surface and a dose of $2000 \mathrm{mg} / \mathrm{kg}$ body weight for two different extracts was applied. The animals were observed and recorded for changes of redness, erythema, sleep pattern, behavior pattern, and mortality for 14 days. Thereafter a skin irritation test was also carried out with the methanol extract over $72 \mathrm{~h}$. Based on acute toxicity studies, two doses were selected. 


\subsection{Grouping of animals and experimental method}

All animals were grouped into nine classes with 8 animals (Table 1). Group 1 mice was treated as normal (no treatment), group 2 mice with standard drug, Retino-A $0.05 \%$ (Tretinoin cream U.S.P.) Janssen-Cilag Pharmaceuticals (Trademark of Johnson \& Johnson, USA) in cream form (positive control), group 3 to 8 mice were administered a daily topical dose of $62.5 \mathrm{mg}$ of $5 \%$ imiquimod cream (Aldara; $3 \mathrm{M}$ Pharmaceuticals, UK) to a $3 \mathrm{~cm} \mathrm{x} 4 \mathrm{~cm}$ shaved area on their backs for 7 consecutive days and they were observed for induced psoriasis. Separately ninth group of animals were kept for comparative study of higher activity of plant extract with isolated compound.

Table 1: Grouping of the animals

\begin{tabular}{|l|l|c|}
\hline Groups & Treatments & No. of animals (n) \\
\hline 1 & Normal (Without extract) & 8 \\
2 & The animals received standard drug (Retino-A 0.05\%) & 8 \\
3 & The induced animals treated with $200 \mathrm{mg} / \mathrm{kg}$. b.w. of PD & 8 \\
4 & The induced animals treated with $200 \mathrm{mg} / \mathrm{kg}$. b.w. of BV & 8 \\
5 & The induced animals treated with $400 \mathrm{mg} / \mathrm{kg}$. b.w. of PD & 8 \\
6 & The induced animals treated with $400 \mathrm{mg} / \mathrm{kg}$. b.w. of BV & 8 \\
7 & The induced animals treated with $200 \mathrm{mg} / \mathrm{kg}$. b.w. of PD and $200 \mathrm{mg} / \mathrm{kg} \mathrm{b.w.} \mathrm{of} \mathrm{BV} \mathrm{in} \mathrm{combination}$ & \\
8 & The induced animals treated with $400 \mathrm{mg} / \mathrm{kg}$. b.w. of PD and $400 \mathrm{mg} / \mathrm{kg} \mathrm{b.w.} \mathrm{of} \mathrm{BV} \mathrm{in} \mathrm{combination}$ & 8 \\
9 & Extract with higher activity + Isolated compound & 8 \\
\hline
\end{tabular}

- $\mathrm{n}=8 ;$ (No. of mice)

Based on the clinical psoriasis area and severity index, the scoring system was carried out (Feldman and Krueger, 2005). Various parameters such as redness, erythema, and scales were scored independently on a scale from 0 to 4 : 0 , none; 1 , slight; 2 , moderate; 3 , marked; and 4, very marked. The cumulative score with scale from 0-12 (sum of redness, erythema, and scaling) was served as a measure of the psoriasis severity index (PSI) (Srivastava et al., 2016). After psoriasis induction to the mice in group 3 to 8 from day 8 onwards extract treatment was started once daily, 5 times a week, for four weeks. At the end of the study, the animals were anesthetized using high dose carbon dioxide gas in a closed desiccator. Skin specimens were collected and preserved in glass bottle containing $10 \%$ formalin solution for further histopathological analysis. Each mice skin specimen with dimension of about $5 \mathrm{~mm}$ diameter and $5 \mu \mathrm{m}$ thickness were prepared by microtome and stained with hematoxylin and eosin ( $\mathrm{H}$ and $\mathrm{E})$ dye for this pathological study.

Epidermal thickness was calculated by measured the distance between the dermal epidermal junction (DEJ) and the beginning of the horny layer. Five measurements per animal were made in every 10 scales and the mean of the different animals was calculated. The change in epidermal thickness was then calculated.

Based on the higher activity, finally combined extract was compared with the isolated Quercetin for anti psoriasis activity.

\subsection{Statistical analysis}

The experimental results were represented as mean \pm standard deviation and analyzed using one-way analysis of variance by Tukey-Kramer multiple comparisons test. The statistical calculations were performed using Graph Pad 5 software (San Diego, CA, USA). $\mathrm{P}<0.05$ was considered statistically significant in all the groups.

\section{Results}

\subsection{Yield of the extracts and phytochemical screening}

Yield of the methanol extract for both the PD and BV plants was calculated and the results are shown in Figure 2. Percentage yield was calculated and it was found that the yield of PD was $48 \%$ and the yield of BV was $43.5 \%$.

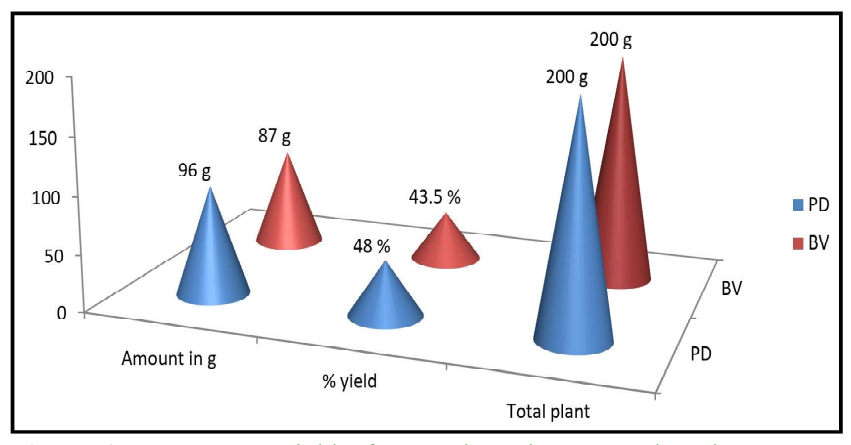

Figure 2: Percentage yield of PD and BV leaves methanol extract.

- $\mathrm{PD}=$ Phlebodium decumanum; $\mathrm{BV}=$ Bauhinia variegata.

Phytochemical screening was carried out for both the plant extracts by chemical tests and revealed the presence of various group of essential phytochemicals which is depicted in Table 2.

Table 2: Phytochemical screening for plant extracts by chemical tests

\begin{tabular}{|l|c|c|}
\hline Chemical test & $\begin{array}{c}\text { Methanol PD } \\
\text { extract }\end{array}$ & $\begin{array}{c}\text { Methanol BV } \\
\text { extract }\end{array}$ \\
\hline Protein & + & + \\
Glycoside & - & + \\
Alkaloids & ++ & ++ \\
Saponins & + & - \\
Flavonoids & ++ & ++ \\
Steroids & ++ & ++ \\
Polyphenols & ++ & - \\
Terpenoids & - & - \\
Tannins & + & + \\
Resins & - & + \\
\hline
\end{tabular}

- $\mathrm{PD}=$ Phlebodium decumanum; $\mathrm{BV}=$ Bauhinia variegate; $(+)=$ Weak positive; $(-)=$ negative; $(++)=$ Strong positive

Thereafter, flavonoid (Quercetin) was identified using standardized mobile phase, toluene: ethyl acetate: Formic acid (7: 5: 1, v/v) and the retention factor $\left(\mathrm{R}_{\mathrm{f}}\right)$ was found 0.66 and 0.67 for Quercetin of $\mathrm{PD}$ and BV methanol extract respectively by compared with standard Quercetin (Figure 3). 


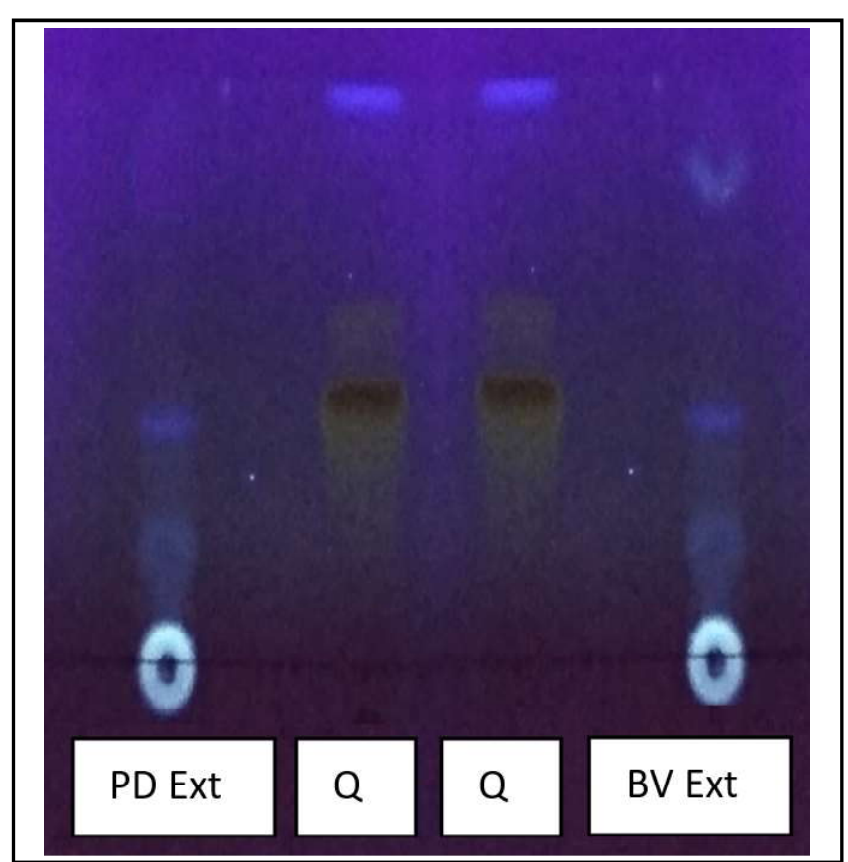

Figure 3: TLC of $\mathrm{BV}$ and $\mathrm{PD}$ methanol extract; $\mathrm{Q}=\mathrm{Quercetin}$.

$20 \mathrm{~g}$ of methanolic extract was subjected to column chromatography and eluted with various solvents, viz., chloroform, ethyl acetate, ethanol and methanol in combination based on the increasing polarity and about 80 fractions were collected to obtain fractions for yellow amorphous powder. The combined solvent ethyl acetate: ethanol (80:20) showed yellow colored fraction that further crystallized (Yield: $45 \mathrm{mg}$ from PD and $39 \mathrm{mg}$ from BV).

Isolated sample further identified with UV-Vis spectrophotometer and FTIR spectroscopy. UV-Vis range was selected from 550 to $190 \mathrm{~nm}$ range and both standard Quercetin and isolated sample were resulted the same graph with two higher peaks of $375 \mathrm{~nm}$ and $250 \mathrm{~nm}$ respectively. Thereafter, FT-IR study preliminary confirmed the isolated sample was Quercetin when standard and sample was performed with FT-IR, the peaks were identical each other which were showed in Figure 4 and 5. The IR data revealed the bond angle between various functional groups present in Quercetin such as, broad absorption peak at $3296.26 \mathrm{~cm}^{-1}$ identified as the $\mathrm{OH}$ stretching vibration of phenolic group. Thereafter, absorption peak at 1668.24 $\mathrm{cm}^{-1}$ confirmed the $\mathrm{C}=\mathrm{O}$ aryl ketonic stretching vibrations whereas, the absorption peaks at $1612.16 \mathrm{~cm}^{-1}, 1516.26 \mathrm{~cm}^{-1}$ and 1429.54 $\mathrm{cm}^{-1}$ are confirmed with the presence of the $\mathrm{C}-\mathrm{C}, \mathrm{C}=\mathrm{O}$ and $\mathrm{C}=\mathrm{C}$ aromatic stretching vibrations respectively. The absorption peak at $1365.37 \mathrm{~cm}^{-1}$ showed the presence of $\mathrm{OH}$ bending vibrations of phenols group. After that, the absorption peak at $1313.58 \mathrm{~cm}^{-1}$ showed the presence of $\mathrm{C}-\mathrm{H}$ bond in aromatic hydrocarbon. C-O stretching vibrations of aryl ether and phenols were observed at 1240.55 $\mathrm{cm}^{-1}$ and $1210.97 \mathrm{~cm}^{-1}$, respectively. C-CO-C stretching and bending vibrations of ketones were observed at $1177.60 \mathrm{~cm}^{-1}$. Further, C-H bending of aromatic hydrocarbons was observed in narrow absorption peaks of $938.70 \mathrm{~cm}^{-1}, 815.04 \mathrm{~cm}^{-1}, 716.65 \mathrm{~cm}^{-1}$ and $579.88 \mathrm{~cm}^{-1}$ that confirms the isolated compound is Quercetin with corresponds to standard Quercetin.

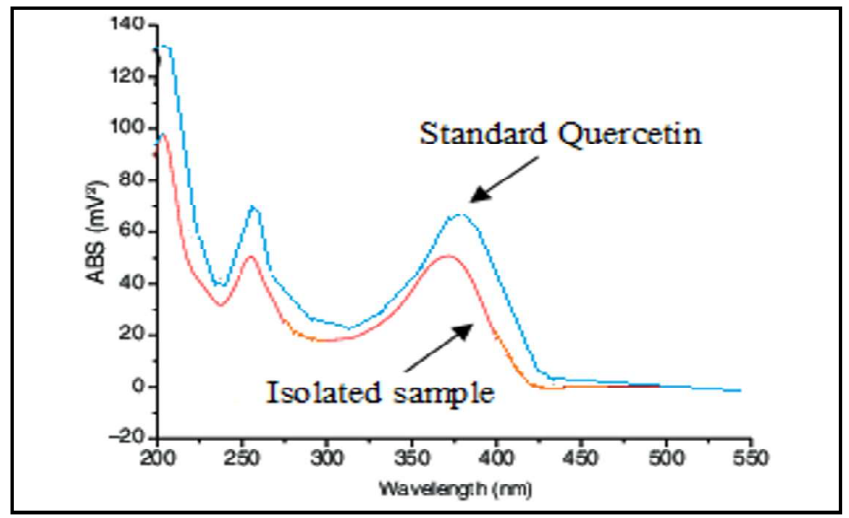

Figure 4: The UV-VIS absorption spectra of standard quercetin peak correspondence with isolated sample.

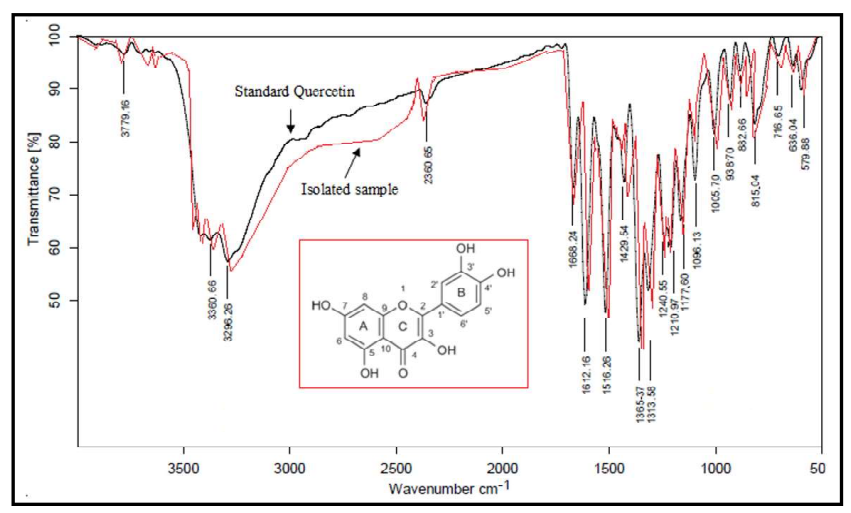

Figure 5: FT-IR study of standard quercetin with correspondence to isolated sample.

\subsection{Acute dermal toxicity}

The study revealed that PD and BV leaf methanol extracts are nontoxic when tested at maximum dose levels of $2000 \mathrm{mg} / \mathrm{kg}$ body weight. No mortality, no sign of toxic reactions or skin irritation were observed during the study period and even after $72 \mathrm{~h}$ of study.

\subsection{Anti psoriasis activity}

$62.5 \mathrm{mg}$ of $5 \%$ imiquimod was applied on mice skin for 7 days and resulted in the development of induced psoriasis in groups 2 to 8 . After 3-4 days, the back skin of the mice started to display signs of erythema, scaling, and thickening (Figure 6).

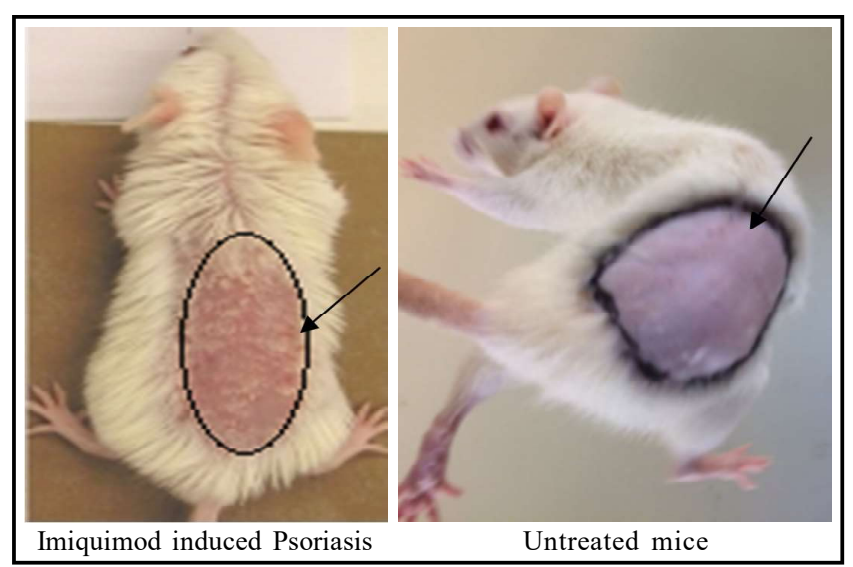

Figure 6: Control and induced psoriasis in mice. 
Various changes such as redness, erythema, and silvery scales on the exposed skin area were visually marked and found an increased up to day 7 and the cumulative score, PSI, was significantly $(p<0.05)$ increased and the result was depicted in Table 3, Figure 7.

Table 3: Examination of various parameters in psoriasis induced mice

\begin{tabular}{|l|l|l|l|l|}
\hline Days & Erythema & Redness & Scales & Cumulative PSI score \\
\hline 1 & 0 & $0.53 \pm 0.21$ & 0 & $0.53 \pm 0.21$ \\
2 & $0.34 \pm 0.40$ & $0.98 \pm 0.11$ & 0 & $1.32 \pm 0.51$ \\
3 & $0.97 \pm 0.22$ & $1.44 \pm 1.03$ & $0.10 \pm 0.11$ & $2.51 \pm 1.36$ \\
4 & $1.53 \pm 0.32$ & $2.10 \pm 0.01$ & $0.42 \pm 0.30$ & $4.05 \pm 0.63$ \\
5 & $2.11 \pm 0.40^{*}$ & $2.99 \pm 0.24^{*}$ & $0.86 \pm 1.21$ & $5.96 \pm 1.85^{*}$ \\
6 & $2.80 \pm 0.20^{*}$ & $3.47 \pm 0.11^{* *}$ & $1.78 \pm 0.20$ & $8.05 \pm 0.51^{* *}$ \\
7 & $3.27 \pm 0.10^{* *}$ & $4.10 \pm 0.31^{* *}$ & $2.27 \pm 1.04^{*}$ & $9.64 \pm 1.45^{* *}$ \\
\hline
\end{tabular}

- PSI: Psoriasis severity index, the results represent mean \pm standard error of mean ( $n=8$ ). Data were analyzed by one way ANOVA, followed by Tukey-Kramer multiple comparisons test, values were considered significant at $* p<0.05$ and $* * p<0.01$

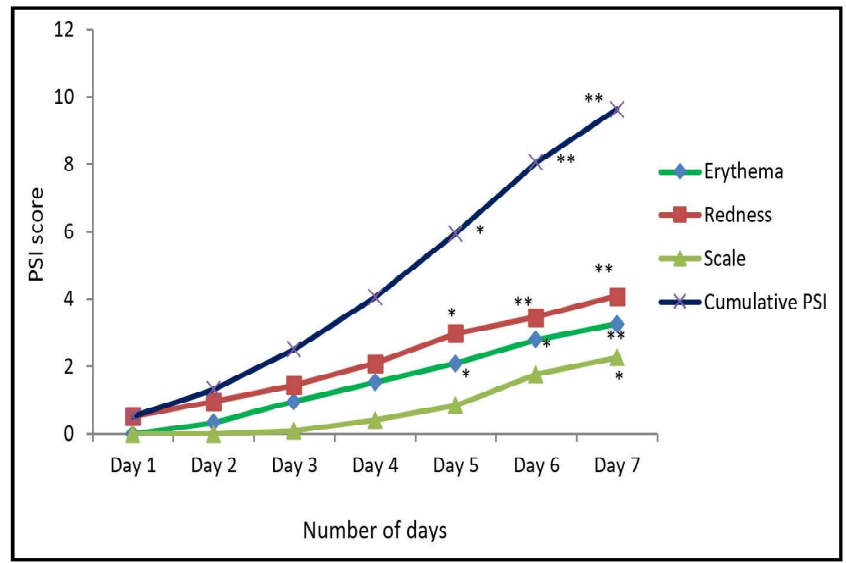

Figure 7: Various Phenotypic changes during Imiquimod induced psoriasis.
After day 7, from day 8 onwards up to 4 weeks the extracts were applied topically to groups $2-8$. The severity of psoriatic lesions was examined by visual as well as histopathological examinations. Group 2 mice which were applied standard drug (received RetinoA cream, $0.05 \%)$ topically, reduced $(p<0.05)$ the severity of redness, erythema, and scales from 7 to 28 days. Furthermore, a drastic reduction $(p<0.01)$ in phenotypic changes like redness, erythema, and scales was observed in groups 7 and 8 , in which combined PD and BV methanol extracts were applied in low $(200 \mathrm{mg})$ and high dose (400 mg). The dose-dependent reduction of various phenotypic changes observed which was statistically significant $\left({ }^{* *} p<0.01\right)$ (Tables 4-6). Thereafter, all the changes were compared only with control, standard drug with higher dose of combined PD+ BV extracts (400 mg) and the correlation was studied (Figure 8, 9 and 10). Interestingly the results showed better therapeutic efficacy by the combined selected said plant samples on induced psoriasis compared to the standard synthetic drug.

Table 4: Evaluation of redness (score 0-4) after treatment with extracts

\begin{tabular}{|l|l|l|l|l|l|l|l|l|}
\hline Days & G-1 & G-2 & G-3 & G-4 & G-5 & G-6 & G-7 & G-8 \\
\hline 7 & $4.10 \pm 0.31$ & $4.12 \pm 0.01$ & $4.13 \pm 0.23$ & $4.20 \pm 0.42$ & $4.11 \pm 0.41$ & $4.14 \pm 0.32$ & $4.12 \pm 0.21$ & $4.10 \pm 0.31$ \\
14 & $4.10 \pm 0.13$ & $2.24 \pm 0.11$ & $3.87 \pm 0.31$ & $3.34 \pm 0.12$ & $3.53 \pm 0.33$ & $3.50 \pm 0.21$ & $2.43 \pm 0.04$ & $2.20 \pm 0.41$ \\
21 & $4.12 \pm 0.01$ & $1.96 \pm 0.21$ & $2.43 \pm 0.21$ & $2.11 \pm 0.31$ & $2.48 \pm 0.11$ & $2.37 \pm 0.02$ & $1.97 \pm 0.03$ & $1.94 \pm 0.22$ \\
28 & $4.14 \pm 0.02$ & $0.59 \pm 0.03^{*}$ & $1.32 \pm 0.04$ & $1.13 \pm 0.03$ & $1.71 \pm 0.01^{*}$ & $1.01 \pm 0.02^{*}$ & $0.57 \pm 0.21^{* *}$ & $0.45 \pm 0.20^{* *}$ \\
\hline
\end{tabular}

- The results represent mean \pm standard error of mean $(n=8)$. Data were analyzed by one way ANOVA, followed by Dunnett comparison test against untreated animals. Values were considered significant at $* p<0.05$ and $* * p<0.01$

Table 5: Evaluation of erythema (score 0-4) after treatment with extracts

\begin{tabular}{|l|l|l|l|l|l|l|l|l|}
\hline Days & G-1 & G-2 & G-3 & G-4 & G-5 & G-6 & G-7 & G-8 \\
\hline 7 & $3.27 \pm 0.20$ & $3.28 \pm 0.12$ & $3.30 \pm 0.20$ & $3.27 \pm 0.42$ & $3.32 \pm 0.41$ & $3.34 \pm 0.32$ & $3.26 \pm 0.21$ & $3.28 \pm 0.32$ \\
14 & $3.28 \pm 0.10$ & $2.02 \pm 0.10$ & $2.87 \pm 0.01$ & $2.74 \pm 0.30$ & $2.53 \pm 0.23$ & $2.28 \pm 0.21$ & $2.04 \pm 0.12$ & $2.00 \pm 0.11$ \\
21 & $3.26 \pm 0.22$ & $1.06 \pm 0.02$ & $2.23 \pm 0.10$ & $2.10 \pm 0.11$ & $1.21 \pm 0.10$ & $1.13 \pm 0.02$ & $1.10 \pm 0.01$ & $0.94 \pm 0.10$ \\
28 & $3.28 \pm 0.12$ & $0.89 \pm 0.11^{*}$ & $1.27 \pm 0.23$ & $1.10 \pm 0.02$ & $1.21 \pm 0.21^{*}$ & $1.08 \pm 0.31^{*}$ & $0.97 \pm 0.01^{* *}$ & $0.84 \pm 0.23^{* *}$ \\
\hline
\end{tabular}

- The results represent mean \pm standard error of mean $(n=8)$. Data were analyzed by one way ANOVA, followed by Dunnett comparison test against untreated animals. Values were considered significant at ${ }^{*} p<0.05$ and $* * p<0.01$

Table 6: Evaluation of scale formation (score 0-4) after treatment with extracts

\begin{tabular}{|l|l|l|l|l|l|l|l|l|}
\hline Days & G-1 & G-2 & G-3 & G-4 & G-5 & G-6 & G-7 & G-8 \\
\hline 7 & $2.27 \pm 0.01$ & $2.30 \pm 0.50$ & $2.33 \pm 0.03$ & $2.32 \pm 0.02$ & $2.32 \pm 0.41$ & $2.30 \pm 0.32$ & $2.28 \pm 0.20$ & $2.26 \pm 0.11$ \\
14 & $2.28 \pm 0.22$ & $2.04 \pm 0.10$ & $2.14 \pm 0.11$ & $2.28 \pm 0.12$ & $2.10 \pm 0.30$ & $2.16 \pm 0.21$ & $2.09 \pm 0.11$ & $1.78 \pm 0.11$ \\
21 & $2.29 \pm 0.31$ & $1.26 \pm 0.33$ & $1.87 \pm 0.01$ & $1.91 \pm 0.01$ & $1.89 \pm 0.32$ & $1.90 \pm 0.12$ & $1.21 \pm 0.22$ & $1.10 \pm 0.21$ \\
28 & $2.32 \pm 0.11$ & $0.79 \pm 0.10^{*}$ & $1.52 \pm 0.22$ & $1.67 \pm 0.01$ & $1.57 \pm 0.21^{*}$ & $1.61 \pm 0.24^{*}$ & $0.74 \pm 0.20^{* *}$ & $0.68 \pm 0.14^{* *}$ \\
\hline
\end{tabular}

- The results represent mean \pm standard error of mean $(n=8)$. Data were analyzed by one way ANOVA, followed by Dunnett comparison test against untreated animals. Values were considered significant at ${ }^{*} \mathrm{p}<0.05$ and ${ }^{*} \mathrm{p}<0.01$ 


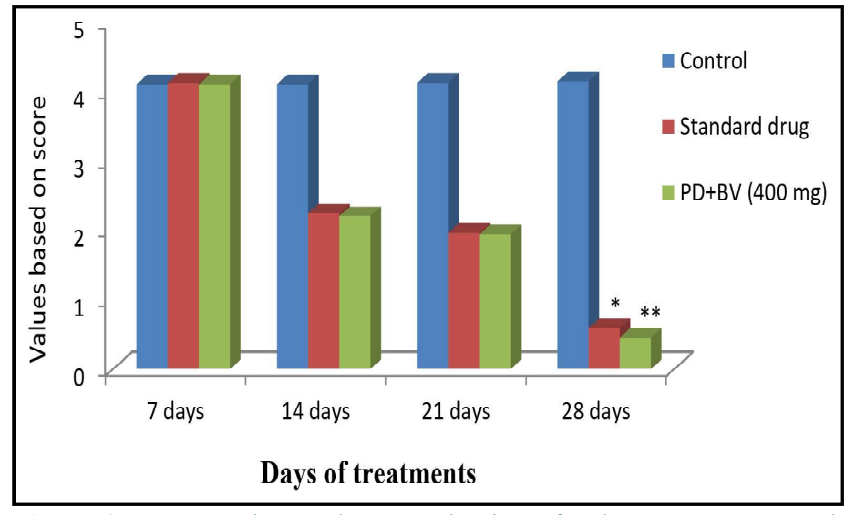

Figure 8: Comparative study on evaluation of redness among control, standard and combined extract of PD+BV (400 mg).

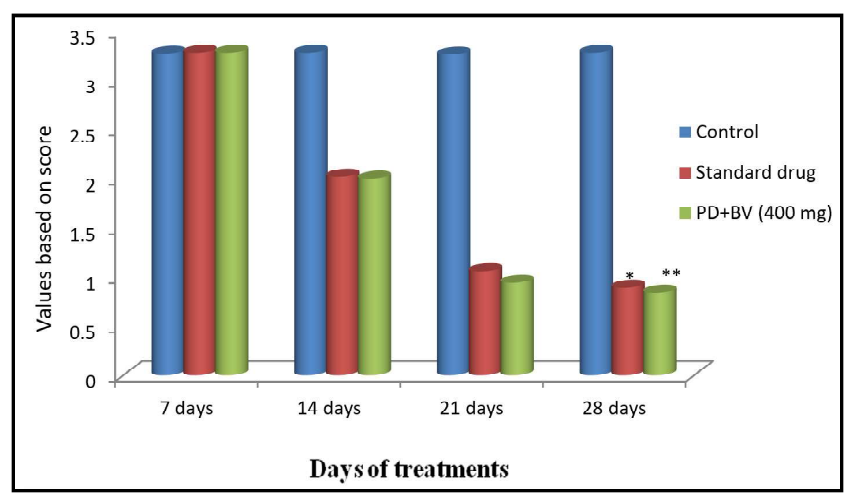

Figure 9: Comparative study on evaluation of erythema among control, standard and combined extract of PD+BV (400 mg).

Epidermal thickness $(\mu \mathrm{M})$ of the skin was measured by digital caliber scale by observed the reduced parakeratosis and granular layer retention that reduced the hyperproliferation of keratinocytes with the initiation of keratinization.

Finally, combined higher dose (400 mg) of PD and BV plant extract was compared with isolated Quercetin with group-9 mice and resulted remarkable reduction of psoriasis in animal in terms of reduction of redness, erythema, and scales formation (Figure 11) after 28 days of study.

\subsection{Histopathological study}

At the end of the study, animals were anesthetized using ketamine, and skin was collected and preserved in glass vials $(10 \%$ formalin in saline solution). About $5 \mu \mathrm{m}$ thickness of longitudinal sections of skin were prepared by microtome and stained with hematoxylin and eosin (H and E) dye. An increased epidermal thickness, hyper proliferation of keratinocytes granulocyte infiltration, the presence of micro abscesses, and capillary loop dilatation were observed in Imiquimod cream induced mouse skin (Figure 12a, b). The epidermal thickness of the experimented animals (treated with extracts) was compared with that of psoriasis induced mice and with the applied standard (Figure 13). The thickness of the epidermal cell was observed very less $(26.04 \mu \mathrm{M})\left({ }^{* *} p<0.01\right)$ with applied extracts of $\mathrm{PD}$ and $\mathrm{BV}$ in combinations ( $400 \mathrm{mg} / \mathrm{kg}$ b.w.) as compared to the standard $(38.11 \mu \mathrm{M})$. Thereafter, isolated Quercetin showed nearly normal skin without any skin lesion, thickness of epidermal cell showed (14.20 $\mu \mathrm{M})$ (Figure 13, 14a, b, c).

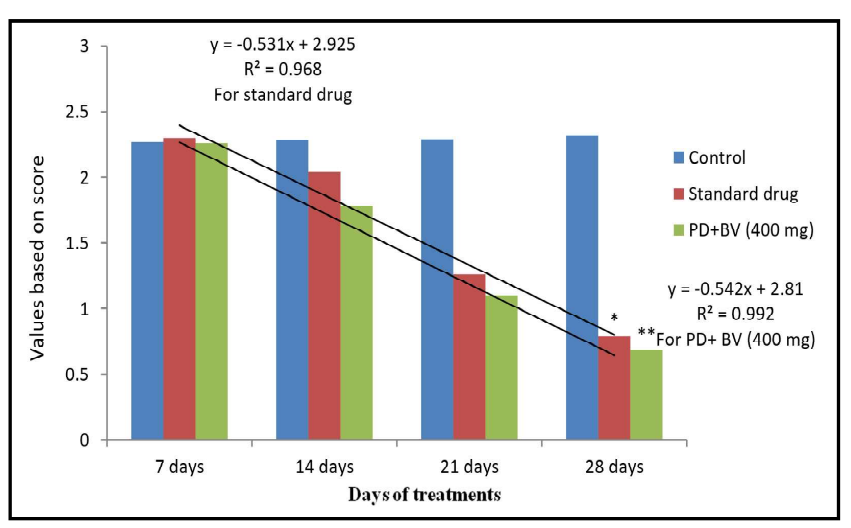

Figure 10: Comparative study on evaluation of scale form among control, standard and combined extract of PD+BV (400 mg).

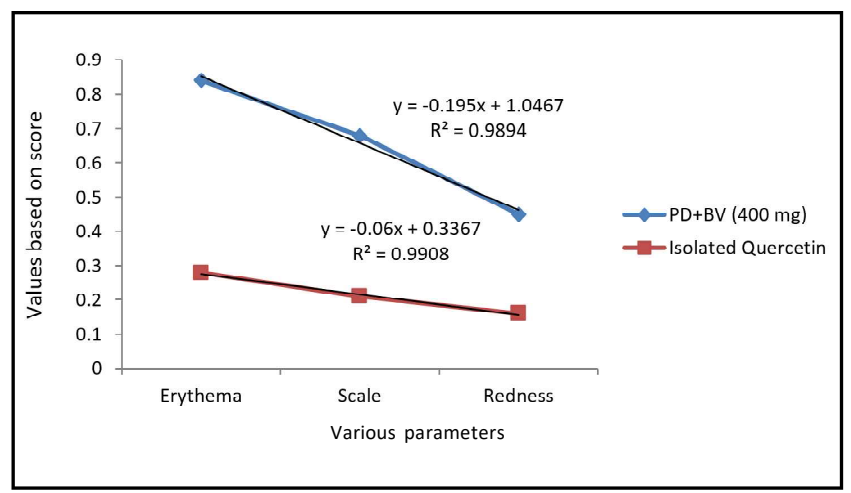

Figure 11: Comparative study of combined extract with isolated Quercetin.

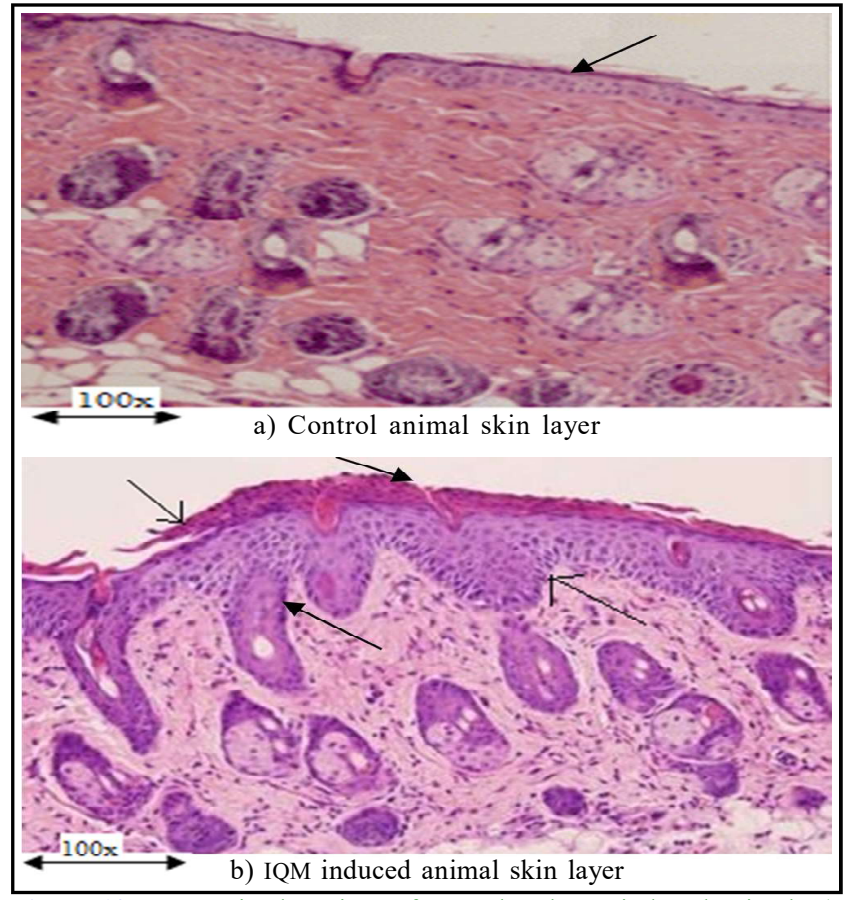

Figure 12: H\&E-stained sections of normal and IQM induced animals a) Arrow indicated that normal animal skin with thin epidermal layer b) Arrows indicated that IQM induced animal skin with epidermal thickening, hyper proliferation of keratinocytes granulocyte infiltration and elongation of cells. 


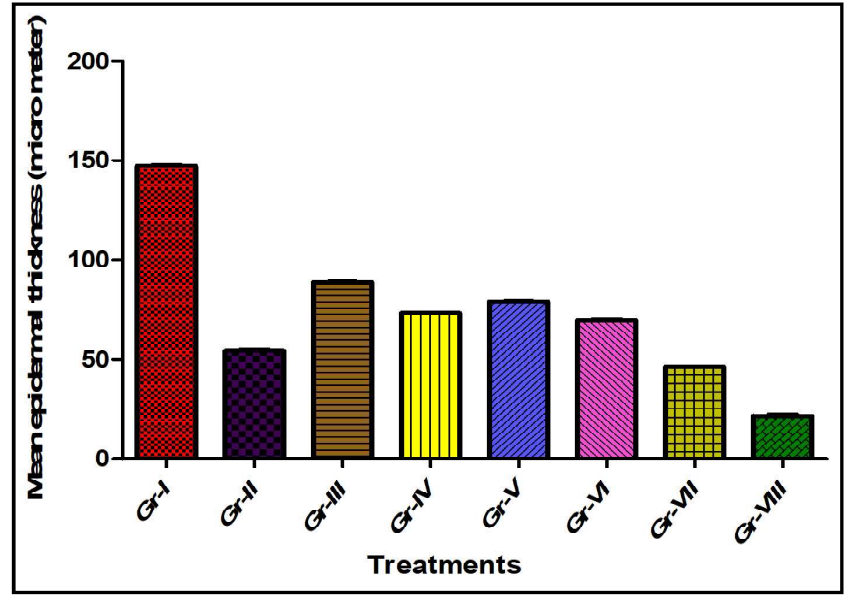

Figure 13: Epidermal thickness among control and extract treated groups.

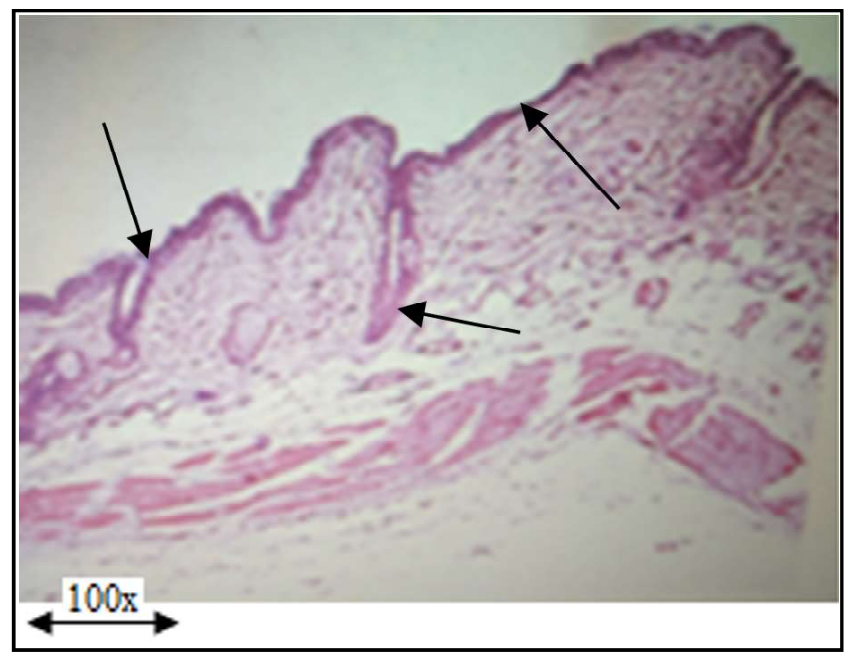

Figure 14b: Recovered skin by treated with plant extracts (thin epidermal layer).

\section{Discussion}

The yield of the extracts showed higher of PD than BV when extracted with methanol solvent. This was due to higher content of phytoconstituents present in the PD than BV which resulted higher yield. Based on the nature of solvent, the extraction of plant constituents varies and also resulted in the quality of the crude extract (Abdelfadel et al., 2016).

Natural medicinal and aromatic plants are applied from ancient time to cure many health related problems. The use of such plants based products are due to their low toxicity, much public acceptance and also low environmental impact (Soylu et al., 2010; Shao et al., 2013). It is evident that fresh plant extracts as well as in combination of plants are very effective against many diseases and that are possible with the presence of many active constituents (Smullen et al., 2007; Cheesman et al., 2017). Based on that, in the present study, the combinations of two drugs were compared with the sole extract for the treatment of psoriasis. However, the isolated compound from both the plant extract showed more potent than the combined extracts against psoriasis treatment. It is evident that isolated compounds are always resulted more therapeutic efficacy

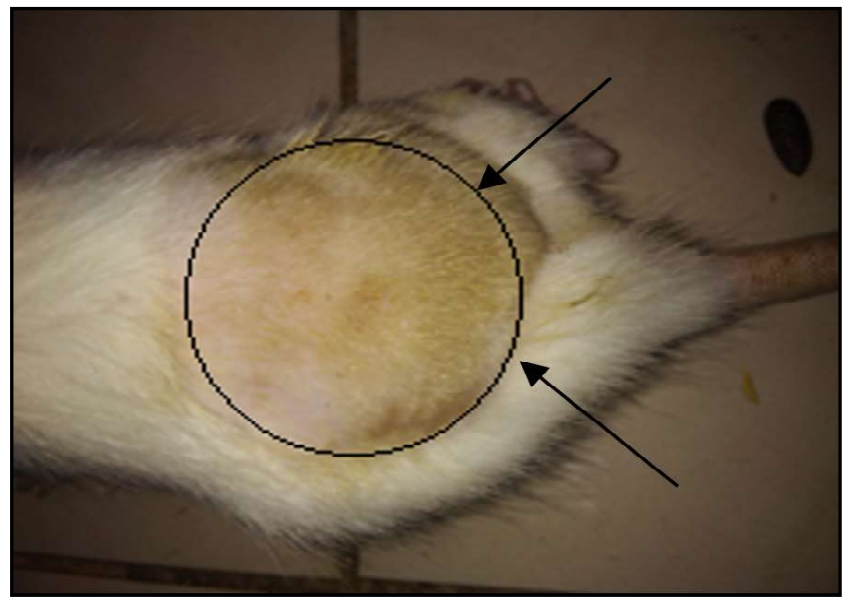

Figure 14a: Recovered skin by plant extracts.

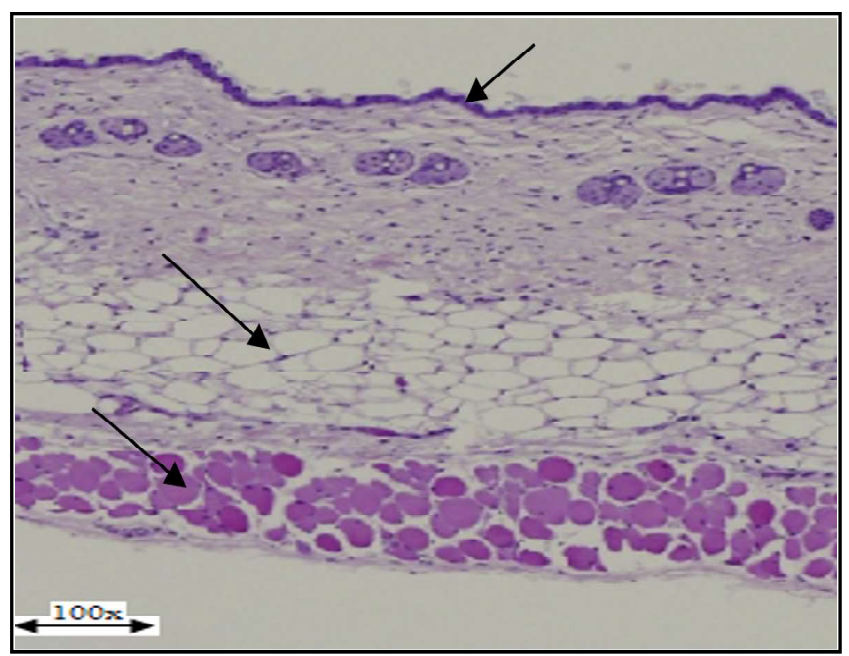

Figure 14c: Recovered skin with isolated quercetin (Arrows indicated Normal thin epidermis, subcutaneous fat and muscle).

than sole or in combined extracts (Vijayalakshmi, and Madhira, 2014; Srividhya et al., 2017). Based on that, the present investigation was carried out for the establishment of anti psoriatic activity of the two plant extracts along with their isolates. Generally, psoriasis is characterized by marked keratinocyte hyper-proliferation, a dense inflammatory infiltrate of T cells, and vascular changes. The main defect was observed as abnormal increase in epidermal cells thickness (Vijayalakshmi, and Madhira, 2014). It has been suggested that an antioxidant treatment is very effective therapy for the management of skin disease such as psoriasis (Young et al., 2008) and polyphenolic compounds are most effective to treat such skin diseases (García Perez et al., 2010). Apart from that polyphenols are having many other potential therapeutic activities such as antioxidative, mild estrogenic, hypolipidemic, antibacterial, antitumor, anti-inflammatory, antidiarrheal, antiulcer, antimutagenic, myocardial protecting, vasodilator, immunomodulator, antiinflammatory, antiproliferative activities (Grimm et al., 2006). Therefore, polyphenolic compounds are advantageous for the treatment of any skin diseases such as psoriasis. Based on that, flavonoid compound (Quercetin) was isolated from the PD and BV plants and studied for anti psoriatic activity. Isolated Quercetin 
was confirmed with UV and IR study which showed similar result reported by Chourasiya et al. (2012). Several mechanisms were available for the management of psoriasis. In the present study, it was revealed that Quercetin enhanced the keratinization process of the skin to protect radiation. The observed anti-psoriatic activity of extracts as well as isolated Quercetin was due to the inhibition of keratinocyte proliferation. The activity was similar with the earlier literatures (Vijayalakshmi, and Madhira, 2014). Quercetin also acts by mechanism that involved the enhancement of antioxidant and anti-inflammatory action and inhibition on the activation of the $\mathrm{NF}-\kappa \mathrm{B}$ signaling (Chen et al., 2017). Histopathological figures revealed a remarkable decreased in relative epidermal thickness with isolated Quercetin and even combined plant extract than the standard drug in psoriasis using a generated imiquimod (IMQ)-induced psoriasis in mouse model. Finally, the results of this study support the use of PD and BV extracts and their isolated flavonoid (Quercetin) can be used as a source of natural antipsoriatic agent and may also useful in some other skin problems.

\section{Conclusion}

Novel plant based compounds endowed with tremendous therapeutic efficacy are the utmost need as leads toward drug discovery in present era. The findings of the present investigation revealed that the combined extracts of PD and CO provide significant dose dependent anti psoriasis activity, even though better than standard drug. Furthermore, isolated flavonoid compound, Quercetin, identified by TLC, UV and IR studies, and showed extremely better activity than combined extract due to its powerful free radical scavenging activity and by inhibited keratinocyte proliferation. Hence, it is always required to establish therapeutic efficacy with the isolated compounds. Further, human clinical trials are needed for the establishment of effective psoriasis treatment using an isolated compound.

\section{Conflict of interest}

The authors declare that there are no conflicts of interest in the course of conducting the research. All the authors had final decision regarding the manuscript and decision to submit the findings for publication.

\section{References}

Abdelfadel, M.M.; Khalaf, H.H.; Sharoba, A.M. and Assous, M. (2016). Effect of extraction methods on antioxidant and antimicrobial activities of some species and herbs extracts. Journal of Food Technology and Nutritional Sciences, 1(1):1-14.

Al-Shafi, A.E. (2013). The pharmacological importance of Bauhinia variegata. A review. Int. J. Pharma Sci. Res., 4(12):160-164.

Boehncke, W.H. and Schon, M.P. (2015). Psoriasis. Lancet., 386(9997): 983 994.

Cheesman, M.J.; Ilanko, A.; Blonk, B. and Cock, I.E. (2017). Developing new antimicrobial therapies: Are synergistic combinations of plant extracts/compounds with conventional antibiotics the solution? Pharmacogn. Rev., 11(22):57-72.

Chen, H.; Lu, C.; Liu, H.; Wang, M.; Zhao, H.; Yan, Y. and Han, L. (2017). Quercetin ameliorates imiquimod-induced psoriasis-like skin inflammation in mice via the NF-אB pathway. Int. Immunopharmacol., 48:110-117.
Chourasiya, A.; Upadhayay, A. and Shukla, R.N. (2012). Isolation of quercetin from the leaves of Azadirachta indica and antidiabetic study of the crude extracts. J. Pharm. Biomed. Sci., 25:179-181.

Das, K. and Einstein, J.W. (2007). Samambaia - The future focus for Indian researchers in the treatment of psoriasis. Thai. J. Pharm. Sci., 31:45-51.

Das, K.; Deb, S. and Karanth, T. (2019). Phytochemical screening and metallic ion content and its impact on the antipsoriasis activity of aqueous leaf extracts of Calendula officinalis and Phlebodium decumanum in an animal experiment Model. Turk. J. Pharm. Sci., 16(3):292-302.

Das, K.; Rekha, R.S.; Ibrahim, M.A. and Ahmed, S.Y. (2017). Effect of demographic location on Phlebodium decumanum (Willd.) J. $\mathrm{Sm}$. for its phytoconstituents and establishment of antioxidant and novel anthelmintic activity of its aqueous and methanolic leaf extracts. Ann. of Phytomed., 6:101-106.

Deng, S.; May, B.H.; Zhang, A.L.; Lu, C. and Xue, C.C. (2014). Topical herbal formulae in the management of psoriasis: Systematic review with meta-analysis of clinical studies and investigation of the pharmacological actions of the main herbs. Phytother. Res., 28: 480-497.

Díaz-Castro, J.; Guisado, R.; Kajarabille, N.; García, C.; Guisado, I.M.; De Teresa, C. and Ochoa, J.J. (2012). Phlebodium decumanum is a natural supplement that ameliorates the oxidative stress and inflammatory signalling induced by strenuous exercise in adult humans. Eur. J. Appl. Physiol., 112:3119-3128.

Feldman, S.R. and Krueger, G.G. (2005). Psoriasis assessment tools in clinical trials. Ann. Rheum Dis., 64(2):65-68.

García-Perez, M.E.; Royer, M.; Duque-Fernandez, A.; Diouf, P.N.; Stevanovic, T. and Pouliot, R. (2010). Antioxidant, toxicological and antiproliferative properties of Canadian polyphenolic extracts on normal and psoriatic keratinocytes. J. Ethnopharmacol., 132:251-258.

Gonzalez-Jurado, J.A.; Pradas, F.; Molina, E.S. and De Teresa, C. (2011). Effect of Phlebodium decumanum on the immune response induced by training in sedentary university students. J. Sports Sci. Med., 10: 315-321.

Grimm, T.; Chovanova, Z.; Muchova, J.; Sumegova, K.; Liptakova, A.; Durackova, Z. and Hogger, P. (2006). Inhibition of NF- $\kappa B$ activation and MMP-9 secretion by plasma of human volunteers after ingestion of maritime pine bark extract (Pycnogenol $($ ). J. Inflamm., 3:1-6

Gupta, A.K.; Vidyapati, T.J. and Chauhan, J.S. (1980). Chemical examination of the stem of Bauhinia variegata. Planta Med., 38:174-176.

Harborne, J.B. (1998). Phytochemical methods: A guide to modern techniques of plant analysis. 3rd ed. Chapman and Hall, London. 302.

Hosoya, E. (1988). Scientific reevaluation of Kampo prescriptions using modern technology. In: Hosoya E, Yamamura Y, editors. Resent advances in the pharmacology of kampo (Japanese herbal) Medicines. Tokyo, Japan: Excerpta Medica, pp:17-29.

Jash, S.K.; Roy, R. and Gorai, D. (2014). Bioactive constituents from Bauhinia variegata Linn. Int. J. Pharm Biomed Res., 5(2):51-54.

Kaur, P.; Robin, Mehta, R.G.; Singh, B. and Arora, S. (2019). Development of aqueous-based multi-herbal combination using principal component analysis and its functional significance in HepG2 cells. BMC Complement Altern. Med., 19:18. https://doi.org/10.1186/s12906019-2432-9.

Kim, G.K. and Del Rosso, J.Q. (2010). Drug-provoked psoriasis: Is it drug induced or drug aggravated? understanding pathophysiology and clinical relevance. J. Clin. Aesthet. Dermatol., 3:32-38. 
Kirtikar, K.R. and Basu, B.D. (1999). Indian Medicinal Plants. Vol I, International Book Distributor, Dehradun. pp:892-901.

Organization Economic for Cooperation and Development (OECD). (2001). Guidelines for testing of chemicals. Acute dermal toxicity, Test No. 402. France: OECD.

Panda, P.K.; Pani, S.R.; Mishra, S. and Sahoo, S. (2011). Nephroprotective effect of Bauhinia variegata (Linn.) whole stem extract against cisplatin-induced nephropathy in rats. Indian Journal of Pharmacology., 43(2):200-202.

Patil, J.K.; Jalalpure, S.S.; Hamid, S. and Ahirra, R.A. (2010). In vitro immunomodulatory activity of extracts of Bauhinia variegata Linn. stem bark on human neutrophils"; Iranian J. of Pharmacology and Therapeutics., 9(2):41-46.

Punzon, C.; Alcaide, A. and Fresno, M. (2003). In vitro anti-inflammatory activity of Phlebodium decumanum. Modulation of tumor necrosis factor and soluble TNF receptors. Int. Immnopharmacol., 3:1293-1299.

Roberson, E.D. and Bowcock, A.M. (2010). Psoriasis genetics: Breaking the barrier. Trends Genet., 26:415-423.

Samuel, M.L.; Donald, P.M. and Hurley, J.H. Jr. (1986). Dermatology. WB Philadelphia: Saunders Company, pp:204.

Sazada, S.; Verma, A.; Rather, A.A.; Jabeen, F. and Meghvansi, M.K. (2009). Preliminary phytochemicals analysis of some important medicinal and aromatic plants. Adv. Biol. Res., 3:188-195.
Shao, X.; Cheng, S.; Wang, H.; Yu, D. and Mungai, C. (2013). The possible mechanism of antifungal action of tea tree oil on Botrytis cinerea. J. Appl. Microbiol., 114:1642-1649.

Smullen, J.; Koutsou, G. A.; Foster, H. A.; Zumbé, A. and Storey, D.M. (2007). The antibacterial activity of plant extracts containing polyphenols against Streptococcus mutans. Caries Research, 41(5):342-349.

Soylu, E.M.; Kurt, S. and Soylu, S. (2010). In vitro and in vivo antifungal activities of the essential oils of various plants against tomato grey mould disease agent Botrytis cinerea. Int. J. Food Microbiol., 143:183-189.

Srivastava, A.K.; Nagar, H.K.; Chandel, H.S. and Ranawat, M.S. (2016). Antipsoriatic activity of ethanolic extract of Woodfordia fruticosa (L.) Kurz flowers in a novel in vivo screening model. Indian J. Pharmacol., 48:531-536.

Srividhya, M.; Hridya, H.; Shanthi, V. and Ramanathan, K. (2017). Bioactive amento flavone isolated from Cassia fistula L. leaves exhibits therapeutic efficacy. Biotech., 7:33-37. DOI 10.1007/s13205-0170599-7.

Vijayalakshmi, A. and Madhira, G. (2014). Anti-psoriatic activity of flavonoids from Cassia tora leaves using the rat ultraviolet B ray photodermatitis model. Rev. Bras. Farma., 24:322-329.

Young, C.N.; Koepke, J.I.; Terlecky, L.J.; Borkin, M.S.; Savoy, L.B. and Terlecky, S.R. (2008). Reactive oxygen species in tumor necrosis factor alpha activated primary human keratinocytes: Implications for psoriasis and inflammatory skin disease. J. Invest. Dermatol., 128:2606-2614.

Citation: Kuntal Das, Adnan A. Khan, V. Gowthami, Vivek Sharma and S. Yahya Ahmed (2020). Mitigation of dermal auto immune disease through combined action of natural constituents: An advantageous over allopathic medicines. Ann. Phytomed., 9(1):162-170. http://dx.doi.org/10.21276/ap.2020.9.1.21 